\title{
Visual Experience Regulates Transient Expression and Dendritic Localization of Fragile X Mental Retardation Protein
}

\author{
Lisa A. Gabel, ${ }^{1 \star}$ Sandra Won, ${ }^{1 \star}$ Hideki Kawai, ${ }^{1}$ Margaret McKinney, ${ }^{1}$ Alan M. Tartakoff, ${ }^{2}$ and Justin R. Fallon ${ }^{1}$ \\ ${ }^{1}$ Department of Neuroscience, Brown University, Providence, Rhode Island 02912, and 2Pathology Department and Cell Biology Program, Case Western \\ Reserve University School of Medicine, Cleveland, Ohio 44106
}

\begin{abstract}
Fragile X syndrome is the most common form of inherited mental retardation and is caused by the loss of function of the Fragile $\mathrm{X}$ mental retardation protein (FMRP). FMRP is an RNA binding protein thought to play a key role in protein synthesis-dependent synaptic plasticity. The regulation of FMRP expression itself is also likely to be an important control point in this process. Here we used darkreared/light-exposed rats to determine the role of experience in regulating FMRP levels in the visual cortex. We find that FMRP levels increase in the cell bodies and dendrites of visual cortical neurons after as little as 15 min of light exposure. Remarkably, FMRP expression in these neurons returns to baseline levels by $30 \mathrm{~min}$ of light exposure. These changes were post-transcriptional because the FMR $1 \mathrm{mRNA}$ levels remained constant over this time period. A transient increase in FMRP levels was also observed in synaptic fractions prepared from visual cortices of light-exposed animals. In contrast, $\alpha$-calcium/calmodulin-dependent kinase II expression showed a sustained upregulation under these conditions. Finally, the increase in FMRP expression was inhibited by blockade of NMDA receptors. This tight temporal-spatial regulation suggests that FMRP plays a dynamic role in a distinct epoch of experience-dependent synaptic plasticity.
\end{abstract}

Key words: Fragile X mental retardation; FMRP; dark reared; synaptoneurosomes; NMDA; mGluR

\section{Introduction}

Fragile X syndrome (FXS) is the most common form of inherited mental retardation. Almost all FXS cases are caused by a triplet repeat expansion in the Fmrl gene, which leads to hypermethylation, transcriptional silencing, and loss of Fragile X mental retardation protein (FMRP) (Jin and Warren, 2003; Willemsen et al., 2004). FMRP is an RNA binding protein that is likely to play an important role in protein synthesis-dependent synaptic plasticity and maturation. It is expressed in cell bodies, at dendritic branch points, and at the origins of spine necks and spine heads (Feng et al., 1997). FMRP represses translation of its target mRNAs, potentially through the RNA interference pathway (Caudy et al., 2002; Mazroui et al., 2002; Jin et al., 2004). FMRP mutant mice show reduced cortical long-term potentiation (LTP) (Li et al., 2002). Although hippocampal LTP is normal, long-term depression in this structure is enhanced in the absence of FMRP (Huber et al., 2002). Finally, abnormalities in synaptic structure are observed in FXS patients, as well as mouse and

\footnotetext{
Received June 4, 2004; revised 0ct. 7, 2004; accepted 0ct. 12, 2004.

This work was supported by National Institutes of Health Grants NS39321, RR15578, and HD044361 and the Fragile X Research Foundation (Newburyport, MA). We thank A. Pastore for constructs and Kathleen Garcia and Garrett Seale for excellent technical assistance. We are also grateful to Joel Richter, Mark Bear, and members of the Fallon laboratory for valuable insights and discussion.

*L.A.G. and S.W. contributed equally to this work.

Correspondence should be addressed to Justin R. Fallon, Department of Neuroscience, Brown University, Box 1953, Providence, RI 02912. E-mail: justin_fallon@brown.edu.

DOI:10.1523/JNEUROSCI.2185-04.2004

Copyright $\odot 2004$ Society for Neuroscience $\quad$ 0270-6474/04/2410579-05\$15.00/0
}

Drosophila models of this disease (Nimchinsky et al., 2001; Galvez et al., 2003; Lee et al., 2003)

The regulation of FMRP expression and localization is likely to be an important control point in synaptic plasticity. Activation of metabotropic glutamate receptors (mGluR) in isolated synaptoneurosomes has been reported to increase both Fmrl mRNA association with polyribosomes and FMRP expression (Weiler et al., 1997). mGluR activation also increases the levels of dendritic FMRP and Fmr1 mRNA trafficking in cultured hippocampal neurons (Antar et al., 2004). FMRP is also increased in barrel cortex synaptic fractions after unilateral whisker stimulation (Todd et al., 2003).

Synapse formation and plasticity are highly dynamic. Key events that mediate and regulate enduring protein synthesisdependent synaptic modifications occur rapidly: on the order of tens of minutes (for review, see Steward and Worley, 2002). Therefore, to understand the role of FMRP in synaptic plasticity in vivo, it is essential to determine the dynamics of its expression and localization. Here we have used the highly tractable darkreared/light-exposed (DR/LE) rat model to study FMRP expression during visual experience-dependent synaptic plasticity. We show that FMRP levels are increased in cell bodies and dendrites of visual cortical neurons within as little as $15 \mathrm{~min}$ of light exposure. Remarkably, FMRP returns to basal levels at a similarly fast pace. Biochemical analysis of synaptic fractions from visual cortex confirmed this FMRP transient expression. Finally, the upregulation of FMRP is posttranscriptional and can be blocked by NMDA receptor (NMDAR) antagonists. These findings suggest 
that FMRP plays a dynamic role in a distinct epoch of experiencedependent synaptic plasticity.

\section{Materials and Methods}

Dark rearing/light exposure. Long-Evans rats reared in complete darkness were used at either postnatal days 44-45 (P44-P45) or P60, as indicated in the figure legends. We observed a similar pattern of FMRP regulation at both ages, but the P45 animals responded faster (see Results). After exposure to ambient light for the indicated periods, DR rats were anesthetized with isofluorane and decapitated, and the primary visual cortices were harvested. For some experiments, DR rats were injected intraperitoneally with CPP [3-2(2 carboxypiperazin-4yl)propyl-1-phosphonic acid] $(10 \mathrm{mg} / \mathrm{kg}) 30 \mathrm{~min}$ before light exposure. The Brown University Animal Care and Use Committee approved all procedures.

Quantitative reverse transcription-PCR. Total RNA from visual cortex was isolated using Trizol (Invitrogen, Carlsbad, CA). First-strand cDNAs primed with oligo-dT were used in quantitative PCR with LUX primers (Invitrogen). Primers were validated as described by the manufacturer. glyceraldehyde-3-phosphate dehydrogenase (GAPDH) transcripts were used to normalize the levels of c-fos and Fmr1.

Synaptoneurosome preparation and Western blot analysis. Synaptoneurosome fractions were prepared as described previously (Quinlan et al., 1999; Wells et al., 2001). Briefly, primary visual cortex was rapidly dissected, disrupted in a glass/glass homogenizer at $4^{\circ} \mathrm{C}$ in PBS with $10 \mathrm{~mm}$ HEPES, 2.0 mм EDTA, 2.0 mм EGTA, 0.5 mм DTT, 0.1 mм PMSF, 10 $\mathrm{mg} / \mathrm{l}$ leupeptin, $50 \mathrm{mg} / \mathrm{l}$ soybean trypsin inhibitor, and $100 \mathrm{~nm}$ microcystin, and passed through two $100 \mu \mathrm{m}$ nylon mesh filters and one $5 \mu \mathrm{m}$ filter. Filtrates were centrifuged at $1000 \times g$ for 10 min to harvest synaptoneurosomes. Equal amounts of total protein (measured using Micro BCA reagents; Pierce, Rockford, IL) were resolved on $7.5 \%$ polyacrylamide gels and transferred to nitrocellulose. To compare the levels of multiple proteins in a single sample, the regions of the blot containing FMRP, $\alpha$-calcium/calmodulin-dependent kinase II ( $\alpha$-CaMKII), and NMDA receptor subunit 1 (NR1), respectively, were excised and probed with anti-FMRP (2F5-1; see below), anti- $\alpha$-CaMKII (Boehringer Mannheim, Indianapolis, IN), or anti-NR1 (BD Biosciences PharMingen, San Diego, CA), followed by an HRP-conjugated secondary antibody. Immunoreactive bands were visualized with ECL plus (Amersham Biosciences, Piscataway, NJ), imaged using the Storm System (Amersham Biosciences), and analyzed with either ImageQuant software (Amersham Biosciences) or NIH Image.

Antibody production. FMR1 null mice (The Jackson Laboratory, Bar Harbor, ME) were immunized with an N-terminal fragment of human FMRP (residues 1-204) produced in bacteria from a cDNA plasmid generously provided by A. Pastore (National Institute for Medical Research, London, UK) (Adinolfi et al., 1999). Hybridomas were screened by ELISA with the same recombinant fragment. Monoclonal antibody 2F5-1 recognizes FMRP on Western blots of HeLa cell extracts (Fig. 1 A). Immunocytochemical and Western blot analysis of wild-type and Fmr 1 knock-out mice demonstrate that 2F5-1 is specific for FMRP (Fig. 1 A, B). (We observed that the 2F5-1 hybridoma was unstable; periodic recloning of the cell line was necessary to obtain consistently high-titer supernatants.)

Immunohistochemistry. Frozen sections from flash-frozen brain were fixed with $100 \%$ methanol for $4 \mathrm{~min}$, followed by $50 \%$ acetone for $2 \mathrm{~min}$ at $-20^{\circ} \mathrm{C}$, treated in $0.5 \% \mathrm{H}_{2} \mathrm{O}_{2}$ in methanol for $30 \mathrm{~min}$ at room temperature, incubated for $5 \mathrm{~min}$ in $0.1 \%$ Triton X-100, followed by $0.1 \%$ Triton X-100 and 5\% NGS in PBS for $30 \mathrm{~min}$ at room temperature. Sections were incubated in anti-FMRP overnight at $4^{\circ} \mathrm{C}$, washed, and incubated with a biotinylated goat anti-mouse IgG (1:200; Vector Laboratories, Burlingame, CA) for $1 \mathrm{hr}$ at room temperature. Bound antibody was detected by streptavidin-HRP visualized with VECTASTAIN elite $\mathrm{ABC}$ and $\mathrm{DAB}$ (Vector Laboratories). For immunofluorescence analysis, Alexa Fluor 488 goat anti-mouse IgG (1:200; Molecular Probes, Eugene, OR) was used as the secondary reagent; nuclei were labeled with 4,6diamino-2-phenylindole (Molecular Probes), and sections were mounted in Permafluor (Thermo Shandon, Pittsburgh, PA). Sections were observed on either a Nikon (Melville, NY) Eclipse or Leica (Exton, PA) confocal microscope. Dendrites that could be unambiguously traced to a neuronal cell body were defined as proximal dendrites.
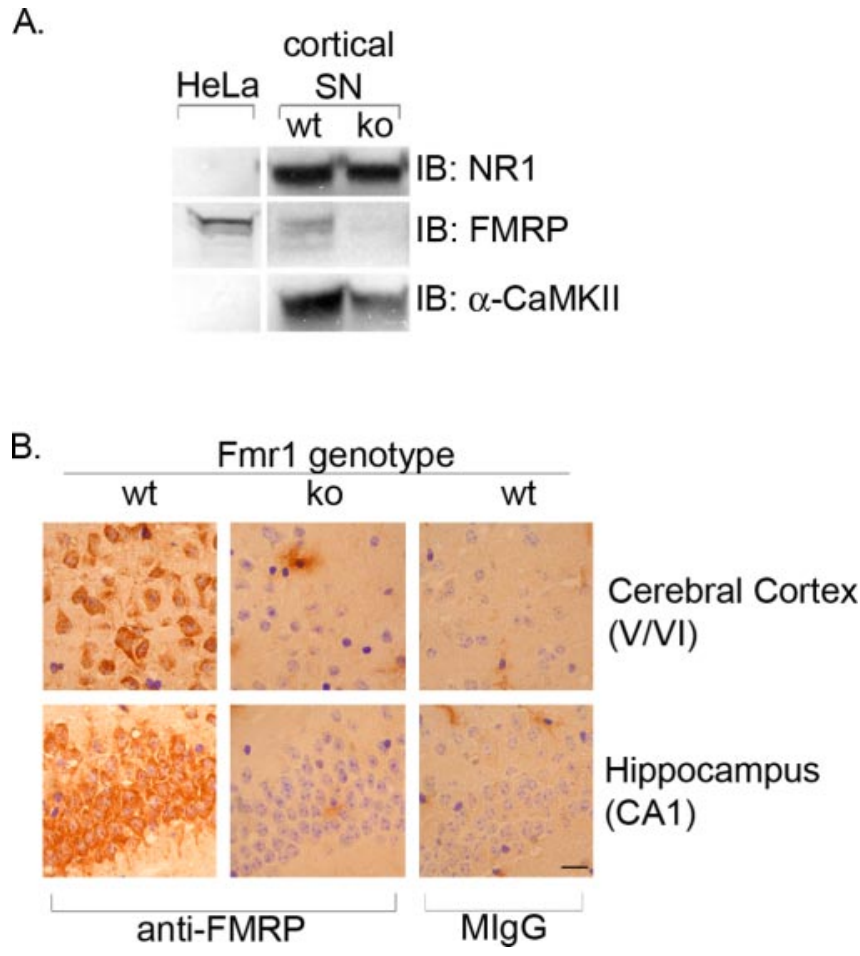

Figure 1. Antibody 2F5-1 is FMRP specific. A, Synaptoneurosome (SN) fractions were prepared from the cortex of wild-type (wt) and Fmr 1 null mice (ko) and probed for FMRP, NR1, and $\alpha$-CaMKII expression by Western blot. HeLa cell extracts are used as a positive control for FMRP expression. $B$, Sagittal sections from wild-type and $F m r 1$ knock-out mice were immunostained with FMRP or normal mouse lgG (MlgG; control). FMRP-positive cells are visible in the cerebral cortex and hippocampus of wild-type mice, but no FMRP-positive cells are detected in Fmr 1 null mice. Scale bar, $10 \mu \mathrm{m}$.

Quantification of FMRP-positive dendrites. $\mathrm{FMRP}^{+}$cells within visual cortical layers II/III and V/VI were counted, as well as the number of $\mathrm{FMRP}^{+}$cells with $\mathrm{FMRP}^{+}$dendrites. The number of $\mathrm{FMRP}^{+}$cells with $\mathrm{FMRP}^{+}$dendrites was divided by the total number of $\mathrm{FMRP}^{+}$cells to obtain the percentage of $\mathrm{FMRP}^{+}$dendrites within layers II/III and V/VI of the visual cortex after 0,15 , or 30 min of light exposure. Approximately 300 neurons were counted within each layer of a single sagittal section for each experimental condition. One to two sections per animal were examined, and a total of two animals per condition were used.

\section{Results}

FMRP expression in neurons is regulated by visual experience We used the DR/LE system to investigate the experience-driven regulation of FMRP. Light exposure of dark-reared rats induces a robust plasticity in the visual cortex, as evidenced by changes in synaptic function, structure, and biochemical composition (Fagiolini et al., 1994; Quinlan et al., 1999). These changes reflect the events that occur during the acquisition and refinement of visual perception in the course of normal postnatal development, primarily in the critical period. A major advantage of the DR/LE system is that the onset of visual experience can be precisely controlled, and the ensuing robust plasticity occurs in a compressed time period.

In the visual cortex of P44-P45 DR rats, FMRP is expressed in neuronal cell bodies and a subpopulation of proximal dendrites (see below) (Fig. 2). Fifteen minutes of visual experience (LE) elicited three distinct changes in FMRP expression. First, the level of FMRP immunoreactivity increased in neuronal cell bodies in layers V/VI ( $n=6$ animals) (Fig. $2 A$ ) and all other layers of the visual cortex (data not shown). Second, visual experience also regulated FMRP expression in proximal dendrites of visual cor- 


\section{A. Layers V/VI}

\section{Light exposure (min)}

$0^{\prime}$
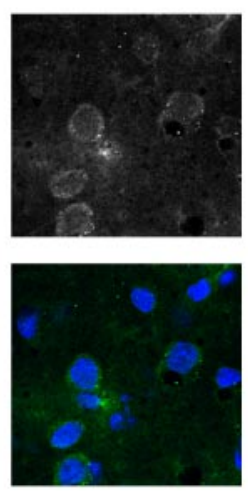

15
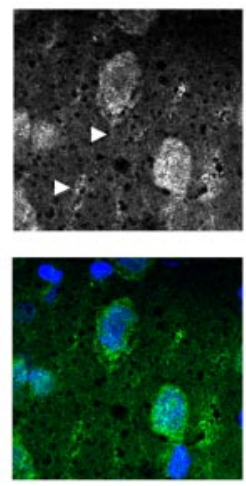

$30^{\prime}$
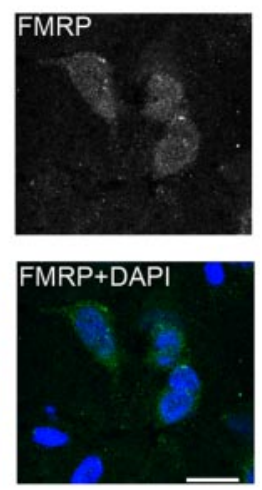

\section{B. Layers V/VI}

\section{Light exposure (min)}

0'
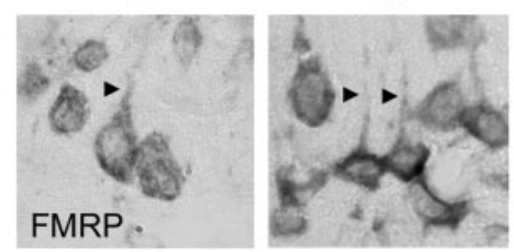

$30^{\prime}$

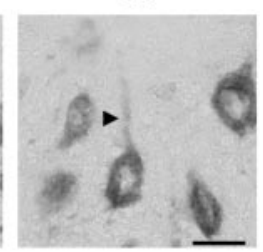

c.

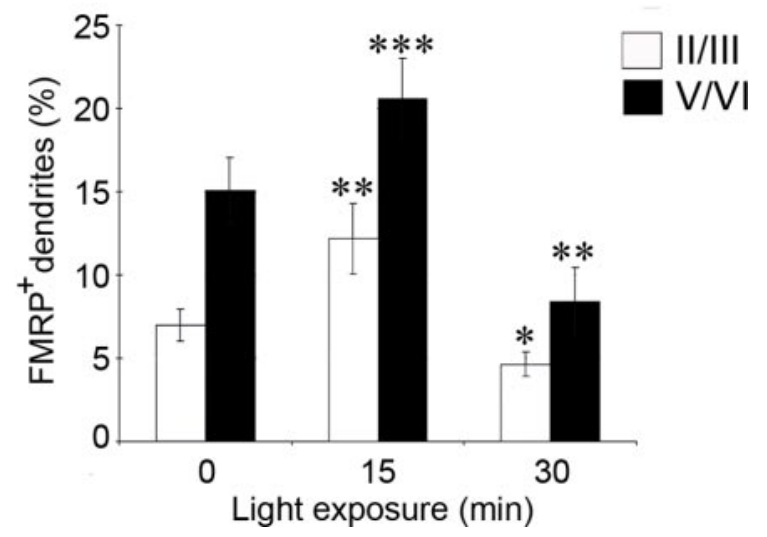

Figure 2. FMRP expression is transiently upregulated in the visual cortex after visual experience. $A$, FMRP-positive cells from visual cortex of P44-P45 dark-reared rats exposed to light for 0,15 , or $30 \mathrm{~min}$. Cells in both layers II/III and V/VI $(A)$ show an increase in FMRP immunofluorescence after $15 \mathrm{~min}$ of light exposure. The increase in FMRP immunoreactivity is attenuated by 30 min of light exposure. FMRP immunoreactivity is not altered by visual experience in CA1 (data not shown). DAPI, 4',6'-Diamidino-2-phenylindole. $B$, FMRP expression in visual cortex layers $\mathrm{V} / \mathrm{VI}$ of dark-reared rats after 0,15 , or 30 min of light exposure. A total of 15 animals, across two litters, were used for immunohistochemical analysis ( 5 animals per condition). Two sections per animal were used to analyze FMRP expression in 300 neurons within layers II/III and V/VI. C, Quantification of the percentage of FMRP-positive cells with FMRPpositive dendrites in layers V/VI and II/III of the visual cortex from dark-reared rats exposed to light for 0,15 , or $30 \mathrm{~min}$. The number of FMRP-positive cells with FMRP-positive dendrites in sagittal sections (10 $\mu \mathrm{m}$ ) was counted as a percentage of the total number of FMRP-positive cells. Student's $t$ tests; ${ }^{*} p<0.04 ;{ }^{* *} p<0.02 ;{ }^{* * *} p<0.001$. Scale bars: $A, B, 10 \mu \mathrm{m}$.

tical neurons (Fig. $2 B, C$ ). In dark-reared animals, the percentage of proximal dendrites with detectable FMRP immunoreactivity was $7.0 \pm 1.0$ and $13.6 \pm 1.5 \%$ in layers II/III and V/VI, respectively (mean \pm SEM; $n=6$ animals; 600-1000 neurons were scored in each layer at each time point). Strikingly, the percentage of FMRP-positive dendrites in visual cortical neurons almost doubled after $15 \mathrm{~min}$ of light exposure (12.2 $\pm 2.1 \%, p<0.02$; layers V/VI, $22.2 \pm 1.8 \%, p<0.001$ in layers II/III and V/VI, respectively). Moreover, this increase in dendritic FMRP was transient: after $30 \mathrm{~min}$ of light exposure, the percentage of immunoreactive dendrites was $4.4 \pm 0.6$ and $8.4 \pm 1.1 \%$ in layers II/III $(p<0.04)$ and V/VI $(p<0.01)$, respectively. Notably, these levels at $30 \mathrm{~min}$ were lower than those of unexposed animals. Third, light exposure induced a transient increase in FMRP expression in the neuropil of the visual cortex (Fig. 2A).

\section{FMRP is transiently upregulated in synaptic fractions from} visual cortex

The transient increase in the neuropil FMRP immunoreactivity noted above suggested that visual experience may regulate FMRP expression in the synaptodendritic domain. To provide additional support for this hypothesis, we used biochemical methods to assess FMRP expression in synaptic fractions. We prepared synaptoneurosomes from visual cortex of either P45 or P60 DR/LE rats and analyzed equal amounts of total protein from them by Western blotting for NR1, $\alpha$-CaMKII, and FMRP levels after light exposure $(0,30$, or 60 min for P60 DR animals; and 0, 15 , and $30 \mathrm{~min}$ for $\mathrm{P} 45 \mathrm{DR}$ animals). In agreement with previous work, NR1 levels, unlike NR2A, do not change in response to light exposure (Fig. 3) (Quinlan et al., 1999; Wells et al., 2001). Furthermore, $\alpha$-CaMKII protein levels in these synaptic fractions were elevated at $30 \mathrm{~min}$ and showed an additional increase after 60 min of light exposure (Fig. $3 A$ ). In contrast, FMRP showed a transient expression pattern with elevated levels observed at 15 min and a return to baseline levels by $30 \mathrm{~min}$ in P45 DR animals (Fig. 3B). A similar profile was observed in P60 DR animals, but with peak expression observed $30 \mathrm{~min}$ after light exposure and a return to baseline by $60 \mathrm{~min}$ of light exposure (Fig. $3 A$ ). Thus, the time course of FMRP expression in synaptic fractions closely reflects that observed in the proximal dendrites and neuropil.

Fmr1 mRNA levels are unchanged by visual experience The increase in FMRP expression that we observe could be a reflection of increased Fmrl mRNA. We therefore performed quantitative reverse transcription (RT)-PCR using RNA from the visual cortex of P45 dark-reared rats exposed to light for 0-60 min. The level of transcripts for GAPDH was used to normalize the level of c-fos and Fmr1. Levels of Fmr1 transcripts do not change with exposure to light (mean $\pm \mathrm{SE} ; 0 \mathrm{~min}, 1.0 \pm 0.0 ; 15$ $\min , 1.0 \pm 0.1 ; 30 \mathrm{~min}, 1.0 \pm 0.1 ; 60 \mathrm{~min}, 0.9 \pm 0.1)$; in contrast, c-fos transcript levels are significantly elevated in response to visual stimulation. (mean $\pm \mathrm{SE} ; 0 \mathrm{~min}, 1.0 \pm 0.0 ; 15 \mathrm{~min}, 5.6 \pm 0.8$; $30 \mathrm{~min}, 7.1 \pm 1.8 ; 60 \mathrm{~min}, 5.7 \pm 1.4$ ) (Fig. 4 ). Thus, the visual experience-induced changes in FMRP expression are regulated at a posttranscriptional level.

\section{The experience-induced expression of FMRP is NMDA receptor dependent}

NMDA receptor activation regulates several aspects of synaptic plasticity, including $\alpha$-CaMKII synthesis in the visual cortex (Bear et al., 1990; Sawtell et al., 1999; Wells et al., 2001). In addition, several studies have demonstrated that FMRP is regulated by mGluR activation, both in vitro and in vivo (Weiler et al., 1997; Todd et al., 2003; Antar et al., 2004). To examine the receptor dependence of the visual experience-induced upregulation of FMRP, we compared rats treated with either NMDA or mGlu receptor antagonists with vehicle-injected animals. To examine 
A.

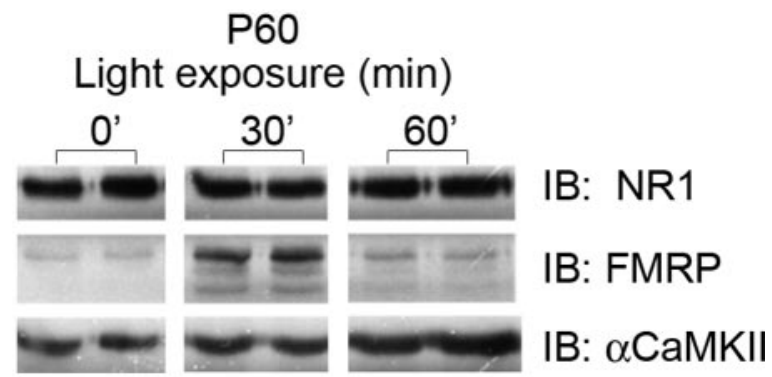

B.

\section{P45}

\section{Light exposure (min)}

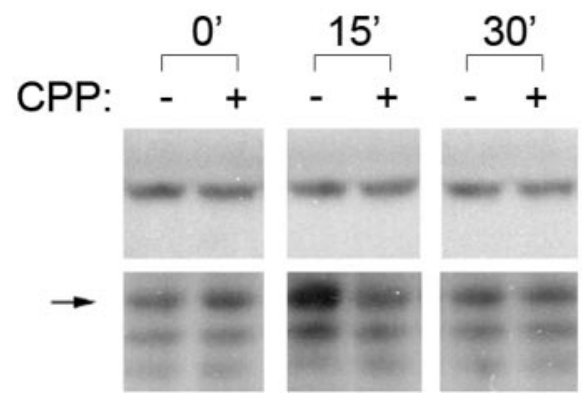

IB: NR1

IB: FMRP

Figure 3. Visual experience induces a transient increase in FMRP levels in synaptoneurosome fractions from visual cortex. $A, P 60$ DR rats were $L E$ for 0,30 , or 60 min. Synaptoneurosome fractions were prepared from the visual cortices and probed for FMRP, NR1, and $\alpha$-CaMKII expression by Western blot. In DR animals of this age (P60), FMRP levels peak at 30 min and return to baseline by $60 \mathrm{~min}$. In contrast, $\alpha$-CaMKII levels are elevated at $30 \mathrm{~min}$ and further increased at $60 \mathrm{~min}$. Each lane shows synaptoneurosome-enriched fractions prepared from the visual cortex of an individual rat. $B$, The upregulation of FMRP induced by visual experience is NMDA receptor dependent. P45 dark-reared rats were exposed to light for the indicated times. The increased expression of FMRP observed at $15 \mathrm{~min}$ of light exposure is blocked by systemic administration of the NMDA receptor antagonist CPP (10 mg/kg). Systemic administration of MPEP $(10-20 \mathrm{mg} / \mathrm{kg}$ ) had no effect on FMRP expression (data not shown).

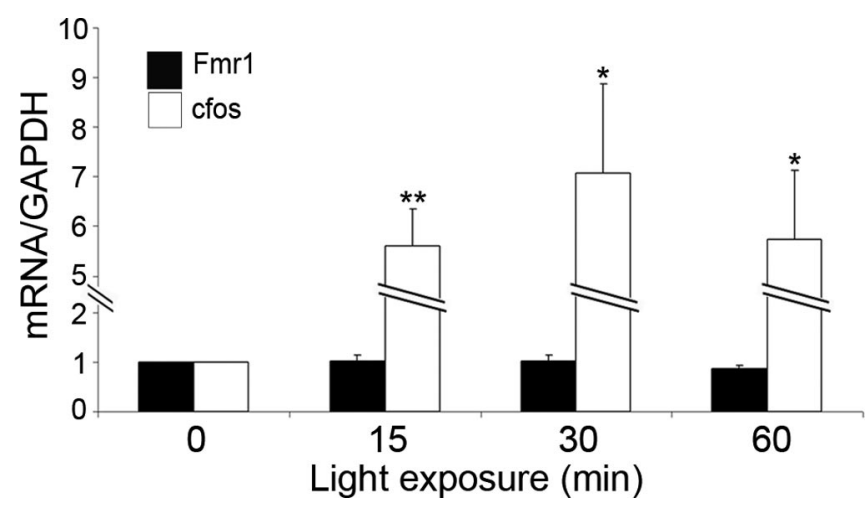

Figure 4. The visual experience-induced increase in FMRP is posttranscriptional. Quantitative RT-PCR using RNA from the visual cortex of P45 dark-reared rats exposed to light for $0-60$ min. GAPDH transcript levels were used to normalize the levels of c-fos and Fmr1. Fmr1 transcript levels do not change with exposure to light, whereas $c-$ fos transcripts are upregulated by visual stimulation at all times examined. Student's $t$ tests; ${ }^{*} p<0.05 ;{ }^{* *} p<0.01$.

the NMDA receptor dependence of this phenomenon, P45 DR rats were injected intraperitoneally with the NMDA receptor antagonist CPP $(10 \mathrm{mg} / \mathrm{kg})$ or vehicle $30 \mathrm{~min}$ before light exposure. DR rats treated with either CPP or vehicle $(n=4$ animals per condition) were exposed to light for $0-30 \mathrm{~min}$. As shown in
Figure 4, CPP treatment blocked the experience-induced increase in FMRP expression. However, CPP did not affect the level of either NR1 or FMRP expression in the DR rats that were not exposed to light. NR1 levels did not change under these conditions. We conclude that NMDAR activation is necessary for experience-induced expression of FMRP in the visual cortex.

\section{Discussion}

FMRP has emerged as a central player in the regulation of protein synthesis-dependent synaptic plasticity. However, we know very little about how FMRP expression itself may be regulated as a function of neural activity in vivo, particularly during the time course over which major changes in synaptic reorganization occur. To address this question, we have determined the role of visual experience in regulating FMRP expression in the visual cortex of DR/LE rats. The most striking finding is that experience induces a rapid but transient expression of FMRP in this system. Furthermore, this transient upregulation of FMRP is observed in both dendrites and cell bodies and requires NMDA receptor activation. Our findings suggest that FMRP plays a dynamic role in experience-induced plasticity, especially during the first $15 \mathrm{~min}$ of synaptic reorganization.

We used both biochemical and immunohistochemical methods to study experience-dependent FMRP regulation. Immunolocalization revealed that, $15 \mathrm{~min}$ after light exposure, FMRP expression was increased in the neuronal cell bodies, proximal dendrites, and neuropil of the visual cortex and returned to baseline (or below) levels by 30 min of light exposure. Quantification of FMRP-immunoreactive proximal dendrites under different conditions confirmed the transient upregulation of FMRP in these structures (Fig. 2). In each experiment, all comparisons were made with littermates that had been reared together. Moreover, all of the tissue harvesting, processing, and analysis were performed in parallel. Together, the transient increase in FMRP immunoreactivity observed in the neuropil and the dynamic FMRP expression detected by biochemical analysis of visual cortical synaptoneurosomes indicates that visual experience regulates FMRP expression in the synaptodendritic domain.

The rapid, transient nature of FMRP expression was an unexpected finding in these studies. This time course stands in marked contrast to that of two other synaptic components in the same preparations: NMDAR1, which does not change, and $\alpha$-CaMKII, which shows a sustained increase over the same time period (Fig. 3) (Wells et al., 2001). This distinct, selective regulation suggests a time window during synaptic plasticity in which FMRP may play a particularly prominent role. Such a temporally restricted function is consistent with the proposal that FMRP is essential for proper synaptic maturation (Huber et al., 2002). Moreover, FMRP has been implicated in several aspects of mRNA dynamics and regulation that could be relevant to the observations reported here. For example, the increased expression at the cell body could reflect the function of FMRP as a nucleocytoplasmic mRNA shuttling element (Bardoni et al., 2003). It is possible that the increase observed in the proximal dendrites and neuropil also marks changes in RNA transport within the cell. Finally, FMRP could be acting to repress the translation of a particular set of target mRNAs in the synaptodendritic domain. It is tempting to speculate that the massive synaptic plasticity that accompanies light exposure could be accompanied by a "reprogramming" of the translational profile at synapses. For example, it may be that FMRP serves to repress the translation of one set of mRNAs, whereas mechanisms, such as CPE/CPEB (cytoplasmic polyadenylation element/cytoplasmic polyadenylation element bind- 
ing protein-mediated polyadenylation), may stimulate protein synthesis from another (Wu et al., 1998; Wells et al., 2001).

A number of studies have implicated mGluR activation in the regulation of FMRP dynamics. We observe that NMDA receptor activity is necessary for FMRP regulation by visual experience. This finding is in agreement with work on barrel cortex, in which NMDA receptor blockade inhibited whisker stimulation-evoked increases in FMRP expression (Todd et al., 2003). We tested 2-methyl-6-(phenylethynyl)-pyridine (MPEP), an mGluR5 inhibitor; however, we could detect no inhibition of FMRP expression in our system (data not shown). Although our results clearly leave open the possibility that mGluR may play a role in experience-induced FMRP regulation in visual cortex, our findings show that NMDA receptor activation is also important in this process. Indeed, it would be surprising if FMRP were regulated by only a single neurotransmitter receptor system.

The molecular mechanisms underlying this dynamic FMRP expression are not known. The quantitative RT-PCR results indicate that the regulation is posttranscriptional (Fig. 4). The rapid loss of FMRP that we observe between 15 and $30 \mathrm{~min}$ of light exposure (in P45 DR animals) strongly suggests protein degradation as one element of this mechanism. Such degradation is likely to be tightly regulated, because it is selective for FMRP (compared with NR1 or $\alpha$-CaMKII) and is observed in all cell compartments studied: cell bodies, proximal dendrites, and synaptodendritic/neuropil. Degradation may involve the ubiquitin system, which has been shown to play an important role in regulating activity-dependent synaptic plasticity (Ehlers, 2003).

The mechanism of FMRP upregulation is unclear. We attempted to ask whether new protein synthesis is involved by treating animals with cycloheximide. However, this treatment by itself (without light exposure) resulted in increased levels of FMRP in synaptoneurosome fractions; light exposure induced no additional changes (our unpublished observations). Because cycloheximide treatment in these same animals blocked the light exposure-induced increase in $\alpha$-CaMKII expression with no effect on its baseline levels (Wells et al., 2001), the FMRP results are unlikely to reflect inefficacy of the drug. Rather, the results suggest a more complex mode for FMRP regulation. One such mechanism could be regulated FMRP degradation. If FMRP has a short half-life, then a transient inhibition of its degradation could lead to an increase in its overall expression. In such a scenario, both the increase and the decrease in FMRP could be regulated at the level of degradation. However, it should be noted that this mechanism would require a much more rapid half-life of FMRP in brain compared with cultured cells $\left(t_{1 / 2} \sim 30 \mathrm{hr}\right.$ in murine fibroblast L-M cells) (Ceman et al., 2003). We are currently developing cell culture models to test these possibilities and to directly measure the rate of synthesis of FMRP.

\section{References}

Adinolfi S, Bagni C, Musco G, Gibson T, Mazzarella L, Pastore A (1999) Dissecting FMR1, the protein responsible for fragile $\mathrm{X}$ syndrome, in its structural and functional domains. RNA 5:1248-1258.

Antar LN, Afroz R, Dictenberg JB, Carroll RC, Bassell GJ (2004) Metabotropic glutamate receptor activation regulates fragile $\mathrm{X}$ mental retardation protein and Fmr1 mRNA localization differentially in dendrites and at synapses. J Neurosci 24:2648-2655.

Bardoni B, Willemsen R, Weiler IJ, Schenck A, Severijnen LA, Hindelang C, Lalli E, Mandel JL (2003) NUFIP1 (nuclear FMRP interacting protein 1) is a nucleocytoplasmic shuttling protein associated with active synaptoneurosomes. Exp Cell Res 289:95-107.

Bear MF, Kleinschmidt A, Gu QA, Singer W (1990) Disruption of experience-dependent synaptic modifications in striate cortex by infusion of an NMDA receptor antagonist. J Neurosci 10:909-925.

Caudy AA, Myers M, Hannon GJ, Hammond SM (2002) Fragile X-related protein and VIG associate with the RNA interference machinery. Genes Dev 16:2491-2496.

Ceman S, O’Donnell WT, Reed M, Patton S, Pohl J, Warren ST (2003) Phosphorylation influences the translation state of FMRP-associated polyribosomes. Hum Mol Genet 12:3295-3305.

Ehlers MD (2003) Eppendorf 2003 prize-winning essay. Ubiquitin and the deconstruction of synapses. Science 302:800-801.

Fagiolini M, Pizzorusso T, Berardi N, Domenici L, Maffei L (1994) Functional postnatal development of the rat primary visual cortex and the role of visual experience: dark rearing and monocular deprivation. Vision Res 34:709-720.

Feng Y, Absher D, Eberhart DE, Brown V, Malter HE, Warren ST (1997) FMRP associates with polyribosomes as an mRNP, and the I304N mutation of severe fragile $\mathrm{X}$ syndrome abolishes this association. Mol Cell $1: 109-118$

Galvez R, Gopal AR, Greenough WT (2003) Somatosensory cortical barrel dendritic abnormalities in a mouse model of the fragile X mental retardation syndrome. Brain Res 971:83-89.

Huber KM, Gallagher SM, Warren ST, Bear MF (2002) Altered synaptic plasticity in a mouse model of fragile $\mathrm{X}$ mental retardation. Proc Natl Acad Sci USA 99:7746-7750.

Jin P, Warren ST (2003) New insights into fragile X syndrome: from molecules to neurobehaviors. Trends Biochem Sci 28:152-158.

Jin P, Zarnescu DC, Ceman S, Nakamoto M, Mowrey J, Jongens TA, Nelson DL, Moses K, Warren ST (2004) Biochemical and genetic interaction between the fragile $\mathrm{X}$ mental retardation protein and the microRNA pathway. Nat Neurosci 7:113-117.

Lee A, Li W, Xu K, Bogert BA, Su K, Gao FB (2003) Control of dendritic development by the Drosophila fragile X-related gene involves the small GTPase Rac1. Development 130:5543-5552.

Li J, Pelletier MR, Perez Velazquez JL, Carlen PL (2002) Reduced cortical synaptic plasticity and GluR1 expression associated with fragile X mental retardation protein deficiency. Mol Cell Neurosci 19:138-151.

Mazroui R, Huot ME, Tremblay S, Filion C, Labelle Y, Khandjian EW (2002) Trapping of messenger RNA by fragile $\mathrm{X}$ mental retardation protein into cytoplasmic granules induces translation repression. Hum Mol Genet 11:3007-3017.

Nimchinsky EA, Oberlander AM, Svoboda K (2001) Abnormal development of dendritic spines in FMR1 knock-out mice. J Neurosci 21:5139-5146.

Quinlan EM, Philpot BD, Huganir RL, Bear MF (1999) Rapid, experiencedependent expression of synaptic NMDA receptors in visual cortex in vivo. Nat Neurosci 2:352-357.

Sawtell NB, Huber KM, Roder JC, Bear MF (1999) Induction of NMDA receptor-dependent long-term depression in visual cortex does not require metabotropic glutamate receptors. J Neurophysiol 82:3594-3597.

Steward O, Worley P (2002) Local synthesis of proteins at synaptic sites on dendrites: role in synaptic plasticity and memory consolidation? Neurobiol Learn Mem 78:508-527.

Todd PK, Malter JS, Mack KJ (2003) Whisker stimulation-dependent translation of FMRP in the barrel cortex requires activation of type I metabotropic glutamate receptors. Brain Res Mol Brain Res 110:267-278.

Weiler IJ, Irwin SA, Klintsova AY, Spencer CM, Brazelton AD, Miyashiro K, Comery TA, Patel B, Eberwine J, Greenough WT (1997) Fragile X mental retardation protein is translated near synapses in response to neurotransmitter activation. Proc Natl Acad Sci USA 94:5395-5400.

Wells D, Dong X, Quinlan E, Huang Y-S, Bear M, Richter J, Fallon J (2001) A role for the cytoplasmic polyadenylation element in NMDA receptorregulated translation in neurons. J Neurosci 21:9541-9548.

Willemsen R, Oostra BA, Bassell GJ, Dictenberg J (2004) The fragile X syndrome: from molecular genetics to neurobiology. Ment Retard Dev Disabil Res Rev 10:60-67.

Wu L, Wells D, Tay J, Mendis D, Abbott MA, Barnitt A, Quinlan E, Heynen A, Fallon JR, Richter JD (1998) CPEB-mediated cytoplasmic polyadenylation and the regulation of experience-dependent translation of alphaCaMKII mRNA at synapses. Neuron 21:1129-1139. 